\title{
An Assessment of various smoking \& smokeless tobacco related habits and their associated oral mucosal lesions within Nagpur district populations
}

\author{
Dr.Swapnil N.Patil ${ }^{1}$, Dr. Sushil B. Naik ${ }^{2}$, Dr. Seema D. Kamble ${ }^{3}$, \\ Dr. Mohammed Atif Khan ${ }^{4}$, Dr.Vandana Kokane ${ }^{5}$ Dr.Pawan Motghare ${ }^{6}$, \\ 1, 2, 3, 4 (Department of Public Health Dentistry, VSPM'S Dental College \& ResearchCentre,Nagpur.MUHS \\ Nashik. India.) \\ 5 (Department of Conservative Dentistry,VSPM'S Dental College and Research Centre,Nagpur.MUHS \\ Nashik.India.) \\ 6 (Department of Oral diagnosis, medicine \& radiology,VSPM'S Dental College and Research \\ Centre,Nagpur.MUHS Nashik.India.)
}

\begin{abstract}
An Epidemiological study was carried out to assess various tobacco related habits and their associated oral mucosal lesions within Nagpur district - Rural / Urban populations. . 4 rural and 4 urban clusters were taken for this study A cluster random sampling technique was used in this study with 100 subjects examined form each cluster. Sample size was 800 subjects including both Rural / Urban populations... Data was collected by conducting interviews and clinical examination. The statistical analysis was done by using SPSS 14.It was observed from this study that, various tobacco related habits were more from rural sectors than urban. Habit of smoking was very common among rural population when compared to smoking in urban population. Habit of chewing tobacco was common in rural population when compared to urban. Increased prevalence of habits of both smoking and chewing were observed among Men. Only few females had the habit of smoking, though the prevalence for chewing tobacco was more than smoking. To conclude from this study, chewing and smoking tobacco habits are existing within our society. Tobacco related oral lesions are also alarmingly high from this study group.
\end{abstract}

Key words: chewing tobacco, oral lesions,population, smoking tobacco ,tobacco habits,

\section{Introduction}

Use of tobacco has a devastating effect on the health and well-being of the public. More than 400,000 Indians die each year as a direct result of cigarette smoking, making it the nation's leading preventable cause of premature mortality. ${ }^{1}$ Worldwide, the picture is even more bleak; with current smoking patterns, about 500 million people alive today will eventually be killed by tobacco use. By 2030, tobacco is expected to be the single biggest cause of death worldwide, accounting for about 10 million deaths per year. ${ }^{2}$ One-half of these deaths will occur among people 35 to 69 years of age, losing an average of 20 to 25 years of life. ${ }^{3}$

The effects of tobacco use on the public's oral health also are alarming. All forms of tobaccoincluding cigarettes, cigars, pipes and smokeless tobacco-have been established as causal for oral and pharyngeal cancer and are responsible for more than 75 percent of deaths caused by these malignancies in the India. 4 Tobacco habits are practiced in various different forms and many of them are specific to certain areas of India. The reasons for the initiation of tobacco use are many. .Generally, the most important reason is a toothrelated complaint $(48 \%)$, followed by peer-group Influence $(38 \%)$. Tooth- related problems were the most common reason for women $(92 \%)$, whereas for men peer-group influence $(58 \%)$ was more important.

The evidence is sufficient to consider smoking a causal factor for adult periodontitis and one-half of the cases in this country may be attributable to cigarette smoking. Tobacco use substantially worsens the prognosis of periodontal therapy and dental implants, impairs oral wound healing and increases the risk of the patient's experiencing a wide range of oral soft tissue changes ${ }^{5}$

Tobacco is addictive, and its use is harmful to health in many ways. If tobacco were to be introduced today, it would not be approved for human consumption anywhere in the world. Both smoked and smokeless tobacco contains the alkaloid, nicotine, which is the main addictive agent. ${ }^{6}$ Smoked as well as unburnt tobacco contains thousands of chemical compounds. Many of these compounds are not only irritants and toxins, but they are also carcinogens. The most potent carcinogens in tobacco are the tobacco-specific nitrosamines, polycyclic aromatic hydrocarbons, and many others. ${ }^{7}$ 
Tobacco habits are practiced in various different forms and many of them are specific to certain areas of India. The reasons for the initiation of tobacco use are many .Generally, the most important reason is a toothrelated complaint $(48 \%)$, followed by peer-group Influence (38\%). Tooth- related problems were the most common reason for women $(92 \%)$, whereas for men peer-group influence $(58 \%)$ was more important. ${ }^{8}$

The global literature is only of limited help in assessing the problem of tobacco use in India, since the dominant and the most researched form of tobacco use globally is cigarette smoking. In India, cigarette smoking comprises a small part of the tobacco smoking problem and a minor part of the overall tobacco problem. ${ }^{9} \mathrm{The}$ major smoking problem in India is beedi smoking, and a large part of the overall tobacco problem is the oral use of smokeless tobacco products. All forms of tobacco use are inferred to be unsafe for human health. ${ }^{10}$

Mere extrapolation of the results of tobacco research in developed countries would, therefore, not provide a full picture of the dimensions of the tobacco problem in India. ${ }^{11}$ The difference in the consumption of tobacco in urban and rural population would be helpful to analysis in detail the various patterns of tobacco use in Nagpur district and help in development and implementation of effective intervention strategies.

\section{Material \& methods}

Study consisted of both Rural and Urban sector with different urban clusters and its population and Rural clusters with its associated population. 4 different clusters from Urban and 4 different clusters from Rural areas were selected. A total of 800 samples were collected by doing a survey within Nagpur district municipal and rural area limits consisting of interviewing the subject regarding various tobacco related habits followed by standardized case history proforma was used along with clinical examination in the field. A cluster sampling was carried out with 100 subjects examined within each cluster.

\section{RESULTS}

The table 1 shows distribution of tobacco related habits in males and females in Urban study population as the table shows that out of 400 study population of urban area about $80 \%$ (320) persons doesn't have any kind of habit (chewing or smoking) out of 320, $142(35.5 \%)$ are male and 178(44.5\%) are females with no habits. Among the persons having some form of tobacco habit $18(4.5 \%)$ \& 51(12.75\%) males have chewing and smoking habit respectively. similarly among the females only $2.75 \%$ (11) females have admitted to got chewing habit (figure 1)

The table 2 shows distribution of tobacco related habits in males and females in Rural study population as the table shows that out of 400 study population of urban area about $52.75 \%$ (211) persons doesn't have any kind of habit (chewing or smoking) out of which $112(28 \%)$ are male and 99(24.75\%) are females without any habits Among the persons having either chewing or smoking tobacco habit $65(16.25 \%)$ \& $72(18 \%)$ males have chewing and smoking habit respectively. similarly among the females only $2 \%$ (8) females have admitted to got smoking habit and $11 \%$ (44) females have chewing form of tobacco habit.(figure 2) The table 3 reveals the distribution of study population according to tobacco habits in geographic study areas i.e.

Urban \& Rural area both. The table shows that out of 800 study population 531 (66.37\%) have no habits while $138(17.25 \%)$ and $131(16.37 \%)$ persons have chewing and smoking habit respectively. In rural population $211(26.37 \%)$ have no habit while 109 (13.62\%) persons have chewing habit and rest 80(10\%) have smoking habit. Similarly in Urban study population 320 (40\%) have no habit while 29 (3.62\%) persons have chewing habit and remaining 51(6.37\%) have smoking habit.(figure 3)

Table 4 Showing the prevalence of different smoking tobacco and smokeless tobacco habits in different age groups. 800 individuals were examined from both Rural / Urban areas within Nagpur. Different habits were pertaining to different age groups.Among the smoking habits: Smoking was most prevalent in age group 21-30 years, 51-above years, ad 10-20 years, with 43individuals(5.37\%) reported in age group 20-30, 31 individuals (3.87\%) reported from age 51-above years, and 22 individuals (2.75\%) reported from age group 1020 years. smoking was maximum predominant in age group 41-50 and moderately predominant from age groups 31-40 years. Among the chewing habits: We can see a maximum predominance of habit of chewable form of tobacco from age group 31-40 years with 44 individuals (5.5\%) involved. When compared to other age groups, second highest predominance was reported from 21-30 years with 28 individuals (3.5\%). Teenage group from (10-20) years had a moderate no. of people indulged in habit of chewing tobacco with 26 subjects (3.25\%).followed by old age group with 23subject (2.87\%) and middle aged group with 17 persons $(2.12 \%)$ (figure 4)

Table 5 Showing different types of habits and their associated lesions. From 800 subjects examined from both Rural / Urban areas within Nagpur, 269 had various habits of either smoking or chewing. In rural area, 189 people had various habits; where as the observed number of people who had habits in urban area was only 80. It was observed from this data, individuals who were indulged in the habit of smoking the Precancerous lesions were reported to be highest (15individuals with $17.44 . \%$ ) in the urban area followed by cancerous lesion (9 
individual with 10.96\%) individual in the rural population. Comprising a total of 29 individual with $33.72 \%$ for lesion in smoking It was also seen from this data, individuals who were indulged in the habit of Tobacco chewing. Precancerous lesions were reported to be the highest (25individuals with 29.06 . \%) in the rural area followed by 18 individual with $20.93 \%$ in urban area. Similarly the table shows distribution of cancerous lesion (11individual with $12.79 \%$ ) in the rural population followed by 3 individual with $3.48 \%$ comprising about 57 individuals with $66.28 \%$ prevalence for lesion due to Chewing tobacco the table also shows the total no. of individual (both urban \& rural) i.e. 86 individual with $10.75 \%$ of lesion prevalence in 800 individual.

\section{FIGURES AND TABLES}

Table 1: Distribution of Urban study population about tobacco related habits \& Gender

\begin{tabular}{|l|l|l|l|}
\hline \multirow{2}{*}{ Type of habit } & Gender & \multirow{2}{*}{ total } \\
\cline { 2 - 3 } & male & female & \\
\hline No habits & $142(35.5 \%)$ & $178(44.5 \%)$ & $320(80 \%)$ \\
\hline Chewing & $18(4.5 \%)$ & $11(2.75 \%)$ & $29(7.25 \%)$ \\
\hline Smoking & $51(12.75 \%)$ & $00(00 \%)$ & $51(12.75 \%)$ \\
\hline Total & $211(52.75 \%)$ & $189(47.25 \%)$ & $400(100 \%)$ \\
\hline
\end{tabular}

Table 2: Distribution of RURAL study population about tobacco related habits \& gender

\begin{tabular}{|l|l|l|l|}
\hline \multirow{2}{*}{ Type of habit } & Gender & \multirow{2}{*}{ total } \\
\cline { 2 - 4 } & male & female & $211(52.75 \%)$ \\
\hline No habits & $112(28 \%)$ & $99(24.75 \%)$ & $109(27.25 \%)$ \\
\hline Chewing & $65(16.25 \%)$ & $44(11 \%)$ & $80(20 \%)$ \\
\hline Smoking & $72(18 \%)$ & $8(2 \%)$ & $400(100 \%)$ \\
\hline Total & $249(62.25 \%)$ & $151(37.75 \%)$ & \multicolumn{2}{|l}{} \\
\hline
\end{tabular}

Table 3: Distribution of study population according to about tobacco related habits in geographic area both urban \& rural

\begin{tabular}{|l|l|l|l|}
\hline \multirow{2}{*}{ Type of habit } & Geographic area & \multirow{2}{*}{ Total } \\
\cline { 2 - 3 } & rural & Urban & \\
\hline No habits & $211(26.37 \%)$ & $320(40 \%)$ & $531(66.37 \%)$ \\
\hline Chewing & $109(13.62 \%)$ & $29(3.62 \%)$ & $138(17.25 \%)$ \\
\hline Smoking & $80(10 \%)$ & $51(6.37 \%)$ & $131(16.37 \%)$ \\
\hline Total & $400(50 \%)$ & $400(50 \%)$ & $800(100 \%)$ \\
\hline
\end{tabular}

Table 4: Distribiution of study population according to tobacco relared habits and age ( both urban \& rural

\begin{tabular}{|c|c|c|c|c|c|c|}
\hline \multirow{2}{*}{$\begin{array}{l}\text { Type of } \\
\text { habit }\end{array}$} & \multicolumn{5}{|l|}{ Age groups } & \multirow{2}{*}{ Total } \\
\hline & $10-20$ yrs & $21-30 \mathrm{yrs}$ & $31-40 y r s$ & $41-50$ yrs & $51 \&$ above & \\
\hline No habits & $167(20.87 \%)$ & $\begin{array}{l}102 \\
(12.75 \%)\end{array}$ & $86(10.75 \%)$ & $\begin{array}{l}127 \\
(15.87 \%)\end{array}$ & $49(6.12 \%)$ & $\begin{array}{l}531 \\
(66.37 \%)\end{array}$ \\
\hline Chewing & $26(3.25 \%)$ & $28(3.5 \%)$ & $44(5.5 \%)$ & $17(2.12 \%)$ & $23(2.87 \%)$ & $\begin{array}{l}138 \\
(17.25 \%)\end{array}$ \\
\hline Smoking & $22(2.75 \%)$ & $43(5.37 \%)$ & $15(1.87 \%)$ & $20(2.5 \%)$ & $31(3.87 \%)$ & $\begin{array}{l}131 \\
(16.37 \%)\end{array}$ \\
\hline Total & $215(26.87 \%)$ & $\begin{array}{l}173 \\
(21.62 \%)\end{array}$ & $\begin{array}{l}145 \\
(18.12 \%)\end{array}$ & $164(20.5 \%)$ & $103(12.87 \%)$ & $800(100 \%)$ \\
\hline
\end{tabular}


An Assessment of various smoking \& smokeless tobacco related habits and their associated oral

Table 5: Distribution of study population according to about tobacco related habits and lesion

\begin{tabular}{|l|l|l|l|l|l|}
\hline \multirow{2}{*}{$\begin{array}{l}\text { Type of } \\
\text { habit }\end{array}$} & \multicolumn{2}{|l|}{ Precancerous lesion } & Cancerous lesion & \multirow{2}{*}{ total } \\
\cline { 2 - 5 } & rural & & Urban & Urban & \\
\hline No habits & $00(00 \%)$ & $00(00 \%)$ & $00(00 \%)$ & $00(00 \%)$ & \\
\hline Chewing & $25(29.06 \%)$ & $18(20.93 \%)$ & $11(12.79 \%)$ & $03(3.48 \%)$ & $57(66.28 \%)$ \\
\hline Smoking & $04(4.65 \%)$ & $15(17.44 \%)$ & $09(10.46 \%)$ & $01(1.16 \%)$ & $29(33.72 \%)$ \\
\hline Total & $29(33.72 \%)$ & $33(38.37 \%)$ & $20(23.25 \%)$ & $04(4.65 \%)$ & $86(100 \%)$ \\
\hline
\end{tabular}

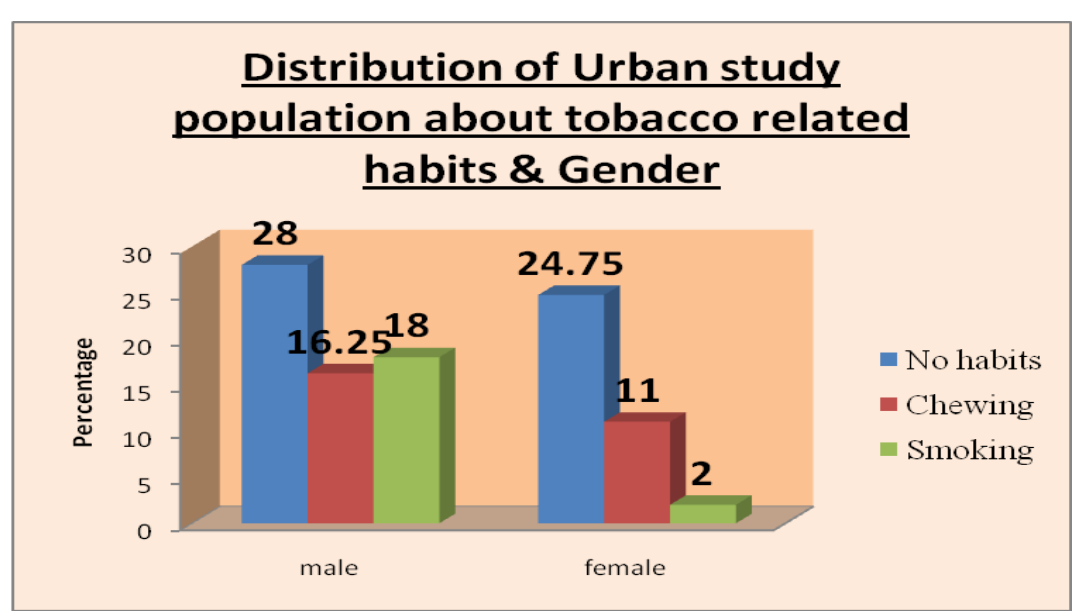

Figure 2 : : Distribution of RURAL study population about tobacco related habits \& gender

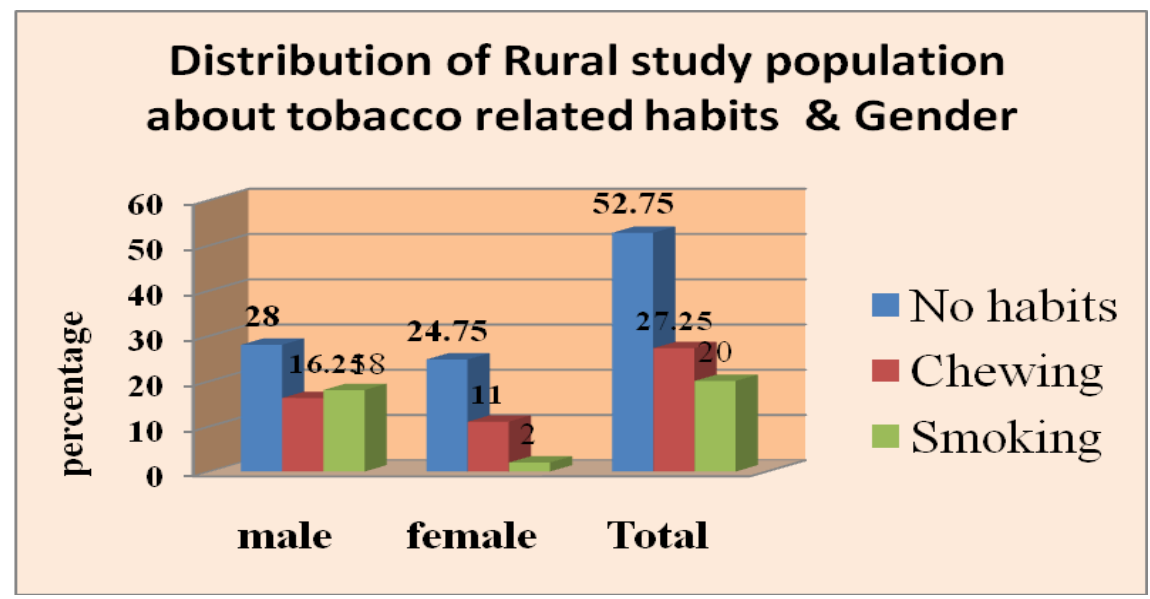

Figure 3: Distribution of study population according to about tobacco related habits in geographic area both urban \& rural

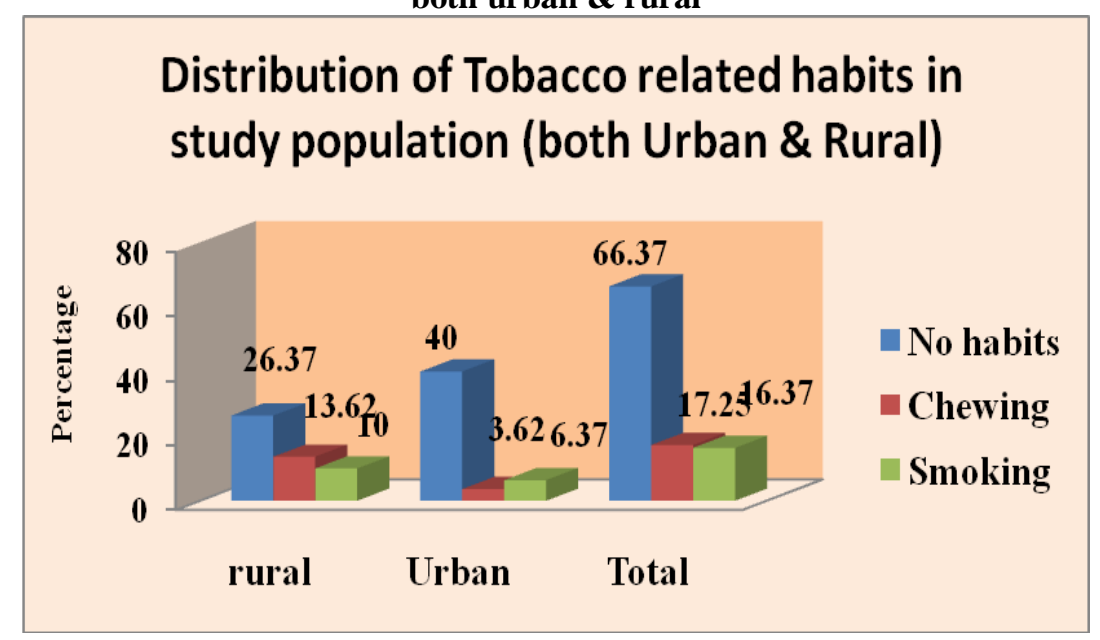


Figure 4: Distribiution of study population according to tobacco relared habits and age ( both urban \& rural)

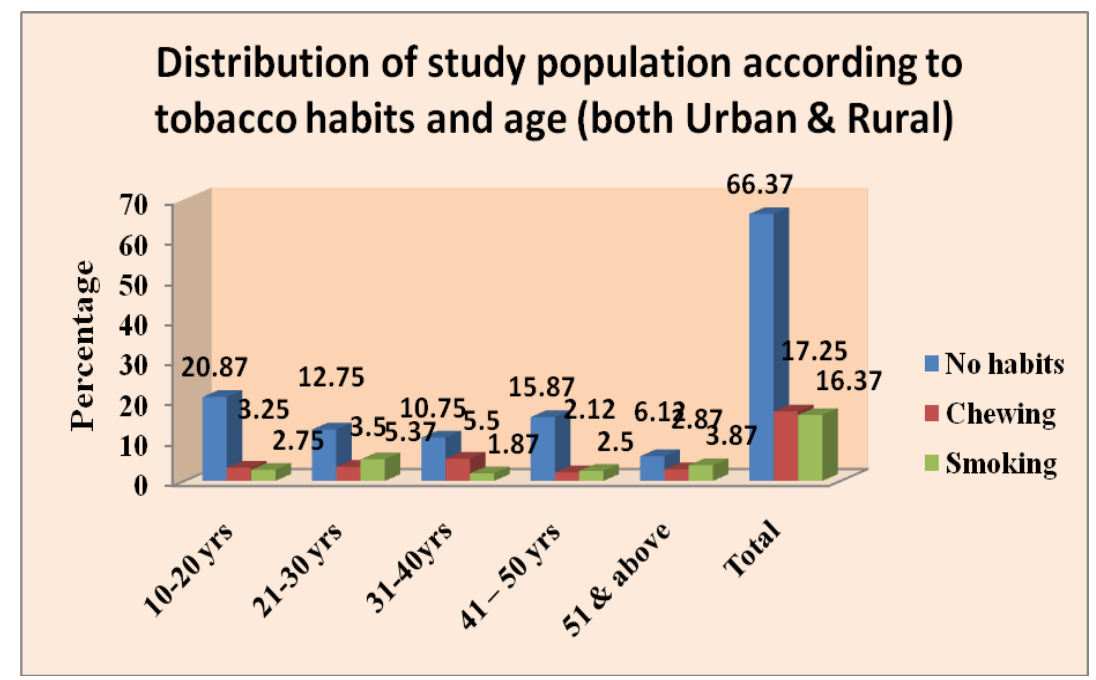

Figure 5: Distribution of study population according to about tobacco related habits and lesion

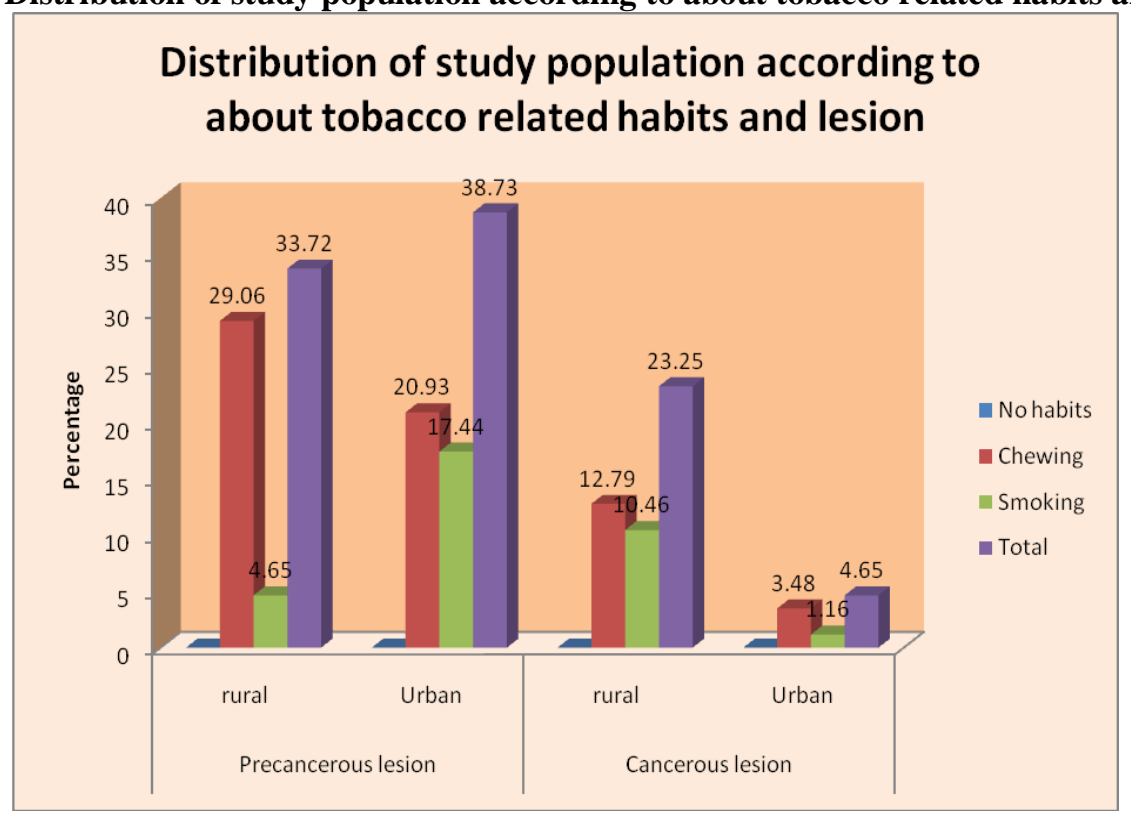

\section{CONCLUSION}

Tobacco use is a risk factor for six of the eight leading causes of death in the world. Smoking tobacco causes cancer of the lung, larynx, kidney, bladder, stomach, colon, oral cavity and esophagus as well as leukaemia, chronic bronchitis, chronic obstructive pulmonary disease, ischaemic heart disease, stroke, miscarriage and premature birth, birth defects and infertility From all these Results we can arise at a conclusion that tobacco use among people are existing and increasing at a higher pace Tobacco related oral lesions are also high, which brings a alarming signal towards development of cancer. So to tackle these problems following recommendations are suggested.

1. Oral health education in regional languages should be given great importance in the media, as it is one of the most effective tools of promotion of oral health.

2. Public should be educated about adverse effects of tobacco and its consequences on oral health as well as on general health of an individual.

3. Tobacco cultivation should be cut down. The farmers, who grow this, should be encouraged to go for other alternative crops and it is the duty of our government to provide support to them.

4. The subjects who sell tobacco products should be provided with viable alternatives to earn their livelihood.

5. Video telefilms on tobacco and its harmful effects should be shown at public places such as railway stations, bus stands etc. 
6. Government should impose ban on advertisement of promotion of tobacco products in media like TV ads and in cinema theatre.

7. Increase the price of tobacco products so that common man cannot afford.

To conclude from this study, Tobacco related oral lesions are also alarmingly high from this study group. However, in near future, further studies with more samples may be required to know the exact proportion of people involved in various habits of smoking and smokeless tobacco.

\section{References}

[1]. Scott L. Tomar;. Dentistry's role in tobacco control JADA, Vol. 132, November 2001)

[2]. Tobacco habits in india.pdf

[3]. Tobacco GATS India Report 2009-2010, The Global Adult Survey (GATS) India, 2009-2010.Ministry of Health and Family Welfare, Government of India, New Delhi.

[4]. Vivek Gupta, Kapil Yadav, Anand K ; Pattern of tobacco use across rural, Urban, and urban- slum population in a North Indian Commuity Indian Journal of Community medicine/ vol 35/issue2/april 2010.

[5]. Gupta PC, Ray CS.; Smokeless tobacco and health in India and South Asia Respirology 2003; 8: 41

[6]. Vendhan Gajalakshmi, Samira Asma, Charles W Warren; Tobacco Survey Among Youth in South India Asian Pacific J Cancer Prev, 5, 273-278)

[7]. Dhirendra N Sinha, Prakash C Gupta; Tobacco Use among school personnel in Orissa ; Indian Journal of Public Health Vol XXXXVIII No.3 July-Sept. 2004 )

[8]. P.C. Gupta ; A study of dose-response relationship between tobacco habits and oral leukoplakia; Br. J. Cancer (1984), 50, 527531)

[9]. Naresh R. Makwana, Viral R. Shah, Sudha Yadav; A Study on Prevalence of Smoking and Tobacco Chewing among Adolescents in rural areas of Jamnagar District, Gujarat State ; JMSR • SEPTEMBER 30, $2007 \cdot 1(1)$

[10]. Raj Narain, Sarita Sardana, Sanjay Gupta* \& Ashok Sehgal Age at initiation \& prevalence of tobacco use among school children in Noida, India: A cross-sectional questionnaire based survey ; Indian J Med Res 133, March 2011, pp 300-30

[11]. Attia Zein AlAbdeen Taha,; Prevalence of Risk-taking Behaviors; CABCM; Bahrain Medical Bulletin, 29, No.4, December 2007 